\title{
Leptospirosis Mimicking Sepsis After Orthopedic Surgery: A Case Report
}

Abboud C. S., Vargas J. and Ferraretto I.
Hospital Infection Control Service Institution: AACD Hospital, São Paulo, SP, Brazil

\begin{abstract}
We report a case of leptospirosis that occurred after elective surgery involving tendon transfer and shoulder arthroscopy. The disease mimicked hospital infection after orthopedic surgery and was at first misdiagnosed as post-operative sepsis. The patient was 60 year old female that developed sepsis with hypotension, shock, bleeding, jaundice and renal insufficiency 4 hours after surgery. Shock treatment procedures were performed and broad spectrum antibiotic therapy was used with coverage for bacteria acquired in hospitals. A careful investigation was carried out by the Hospital Infection Control Service in search of the possible source of the infection. After clinical evaluation by a specialist in infectious diseases, the hypothesis of leptospirosis was put forward based on clinical and epidemiological data. The hypothesis was later confirmed by the positive result of serological tests with the microagglutination method that yielded 1:800 and then 1:12,600 7 days later. This is the first reported case of leptospirosis manifest directly following surgery, mimicking postoperative sepsis.

Key Words: Leptospirosis, sepsis, orthopedic surgery.
\end{abstract}

Leptospirosis is an infectious disease caused by spirochetes of the Leptospira genus. It is characterized as being a zoonosis which affects both wild and domestic mammals. The epidemiology of the infection in humans is related to their direct or indirect contact with contaminated animals.

Initial symptoms may be unspecific, oligosymptomatic, and some cases have severe clinical manifestations including high temperature, hypotension, and the icterohemorrhagic or hepatorenal syndrome known as Weil's syndrome $[1,2]$.

The diagnosis of leptospirosis is very difficult due to its clinical complexity, especially when complete historical data and epidemiological antecedents are

Received on 19 February 2001; revised 4 October 2001.

Address for correspondence: Dr. Abboud C. S. Av. Prof. Ascendino Reis, 724 , Vila Clementino - São Paulo - SP. Zip Code: 04027-000. Phone: 5511 576 0727. Fax: 55115755002

E-mail address: celyabboud@uol.com.br

The Brazilian Journal of Infectious Diseases 2001;5(5):277-279 (C) 2001 by The Brazilian Journal of Infectious Diseases and Contexto Publishing. All rights reserved.

1413-8670 not available. Its endemic nature is strictly related to the population growth among the poor. The geographic areas inhabited by the poor are not adequately urbanized; there are no sanitation facilities, and rats are very common. In the summer, the rainfall rate increases, and floods occur which favor the appearance of this disease in endemic areas [3-5].

In Brazil, leptospirosis has been growing in the last decades and has proven to be an urban disease associated with high mortality [6].

Because it is prevalent in São Paulo in the summer, when rainfall is high, leptospirosis is usually diagnosed in general hospitals or in emergency clinics, although there may be diagnostic confusion with dengue fever where it is endemic [6].

There is no case of leptospirosis reported in the medical literature which was manifest in a patient after any kind of surgery, even in regions where it is endemic. A case was reported in which a patient was in an ICU with sepsis supposedly attributed to biliary tract obstruction. The patient was operated on but no biliary tract obstruction was found; leptospirosis was later diagnosed [7]. 
What is peculiar about the present case is the fact that the disease manifested itself right after orthopedic surgery, mimicking nosocomial septicemia. The possible causes of the disease were investigated by the Hospital Infection Control Service.

\section{Case Report}

A 60 year old middle-class female patient from São Paulo (urban area) was admitted to the AACD Hospital in February, 1999, for elective surgery of tendon transfer and shoulder arthroscopy, with no complication during the surgical act. Four hours after the end of the procedure she had fever, drowsiness, hypotension, and poor peripheral perfusion, and was transferred to the ICU. Six hours later, she had diffuse petechiæand bleeding in the surgical wound.

Septic shock was hypothesized and several measures were introduced for the treatment of the shock including antibiotics (vancomycin and imipenem). During its evolution, there was jaundice (total bilirubin: $14.3 \mathrm{mg} / \mathrm{dl}$, indirect bilirubin: $6.0 \mathrm{mg} / \mathrm{dl}$ and direct bilirubin: $8.3 \mathrm{mg} / \mathrm{dl}$ ), oliguria, petechia increase (platelet count: $98,000 / \mathrm{mm}^{3}$ ), and both alveolar and high digestive bleeding, along with bigeminy in the electrocardiogram and coma. In its evolution, there was acute renal insufficiency (urea: 206 $\mathrm{mg} / \mathrm{dl}$ and creatinine: $5.3 \mathrm{mg} / \mathrm{dl})$, leukocytosis $(36,000$ leukocytes), worsening of the low platelet count (platelets: $\left.51,000 / \mathrm{mm}^{3}\right)$, increase of CPK $(1,766 \mathrm{u} / \mathrm{l}), \mathrm{X}$-ray with diffuse pulmonary infiltrate, and all cultures (blood and urine culture) yielding negative results.

As a result of the serious condition of the patient, the evaluation of an infectious diseases specialist from the Institution was requested. Based on clinical data (septicemia, jaundice, bleeding, petechia increase, and renal insufficiency), Weil syndrome was hypothesized. The epidemiological data was reported by her relatives, who said that she had the habit of cleaning the backyard after storms and that rats were present on those occasions.

Serological testing for leptospirosis (microscopic microagglutination method) yielded: Leptospira pomona $1 / 800$ and after 5 days, $1 / 12,600$. The patient died 7 days after the surgical intervention. No autopsy was performed.

\section{Discussion}

As the patient had symptoms of sepsis immediately after surgery, the initial hypothesis was hospital infection. A search was started in the Surgical Center for probable infection sources, although the infection rates at the hospital, which is generally meant to reflect orthopedic and neurological surgery, were under $1 \%$ and no outbreak or other similar case had been detected. No problem was detected in the Surgical Center and the diagnosis of leptospirosis was based on clinical and epidemiological data, since the patient's relatives reported that in the rainy season her backyard was often flooded and she used to clean it after the flood. Even though the city had cases of leptospirosis at that time of year which were often manifest as septicemia, the diagnosis was not reached immediately because the patient had undergone surgery. For this reason, the hospital staff initially hypothesized that this was a case of postoperative sepsis. The presence of an infectious diseases specialist was fundamental for the correct diagnosis to be established, since both clinical and epidemiological aspects of the disease had to be taken into account.

Due to the unique nature of the case and the fact that it is not reported in the leptospirosis literature with differential diagnosis of post-surgical hospital infection, we suggest that physicians and hospital infection control professionals be aware of this differential diagnosis, mainly in regions with endemic leptospirosis.

\section{References}

1. Tappero J. W., Ashford D. A, Perkins B. A. Leptospira species (Leptospirosis). In: Mandell G. L., Bennet J. E., Dollin R.eds. Principles and Pratices of Infectious Dieases. $5^{\circ}$ ed. New York, N Y, Churcill Livingstone, 2000.

2. Resano A.B., Camino O.B., Urbe P.K. Leptospirosis. Review of five cases. Ann Med Intern 1999;16(10):527-9.

3. Viviane M., Berlot G., Poldini F., et al. Leptospirosi Descrizione di un caso clinico e revisione della letteratura. Minerva Anestesologica 1998;64(10):465-9. 
4. Uip D., Melheus M.S.C., Kawarabayashi M., et al. Achados clínicos epidemiológicos e laboratoriais em pacientes com leptospirose. Rev Bras Med 1992;49(5):225-37.

5. Gonçalves A.J.R., Cunha R.Q., Seabra J.J., et al. Leptospirose: reflexões sobre o espectro grave. Arq Bras Med 1989;63(6):453-9.

6. Ko A.I., Galvão O., Reis M., et al. Urban epidemic of severe leptospirosis on Brazil. Salvador Leptospirosis Study Group. lancet 1999;354(9181):820-5.

7. Garrido R., Castilho L., Hernandez G., et al. Leptospirosis sistémica: Una etiología de falla multiorgánica en un caso. Rev Med Chile 1996;124:359-62. 